\title{
Contracting for Competitive Supply Chains under Network Externalities and Demand Uncertainty
}

\author{
Xiaojing Liu \\ School of Management and Economics, University of Electronic Science and Technology of China, Chengdu 611731, China \\ Correspondence should be addressed to Xiaojing Liu; xiaojingyidu@163.com
}

Received 1 January 2016; Accepted 15 March 2016

Academic Editor: Elmetwally Elabbasy

Copyright (C) 2016 Xiaojing Liu. This is an open access article distributed under the Creative Commons Attribution License, which permits unrestricted use, distribution, and reproduction in any medium, provided the original work is properly cited.

\begin{abstract}
Based on network externalities and demand uncertainty environment, supply chain competition model is built; we identify the valid mechanism for the alternative range of profit-sharing contracts and also analyze the effect of product substitutability coefficient and network externalities on the alliance and profit-sharing contract. The results show that the vertical alliance contributes profit improvement to both the manufacturer and the retailer when the impact of network externalities on the product substitutability is not strong. However, vertical alliance will be out of operation when the effect of network externalities on the product substitutability is strong.
\end{abstract}

\section{Introduction}

In many industries, the competition among enterprises is evolving to supply chain competition (Boyaci and Gallego [1], Barnes [2], Majumder and Srinivasan [3], and Ai et al. [4]). Deloitte investigated more than 200 large-scale industries and proposed this point in its research report. In the report, the industries exhibit network externalities, for example, automotive manufacturing, consumer products, high technology products, and telecommunications.

Katz and Shapiro $[5,6]$ propose that, in the presence of network externalities, more people use the product, and the customer could obtain more utility from purchasing the product. Katz and Shapiro [7] consider market competition between systems and network effects. Chou and Shy [8] use the Hotelling model and conclude that both the market share and the amount of a software increase when the compatibility of the software increases. For a duopoly durable goods market, Xie and Sirbu [9] use a differential game and examine the dynamic pricing behaviors when the market faces price competition and strong demand externalities. Cottrell and Koput [10] use a case study and estimate that software variety has an effect on hardware price. Baake and Boom [11] consider the equilibrium in a model with vertical product differentiation and network externalities. Foros and
Hansen [12] consider a two-stage game which exhibits positive network externalities between two competitive internet service providers. They demonstrate that if the products are vertically differentiated, the firm which provides the superior product would have the larger market share. Doganoglu and Grzybowski [13] propose the symmetric subgame perfect equilibrium in a two-period competition facing switching costs and network effects. They present that as network effects increase, two-period equilibrium prices tend to be lower. Viswanathan [14] uses spatial differentiation model and analyzes the impact of network externalities on technologydifferentiated channels competition. The analysis indicates that consumers can benefit from network externalities under competition.

Hoernig [15] studies strategic delegation in a price competition model with network externalities by considering the complementary or alternative strategies. Chirco and Scrimitore [16] investigate the impact of network externalities on the strategic choice by comparing the pp subgame, qq subgame, and pq subgame. H.-C. Chen and C.-C. Chen [17] analyze the equilibrium behavior in the context of Cournot competition with product differentiation and network externalities. Under product compatibility, they show that, due to higher spillover effect, a firm has a greater competitive disadvantage when degree of compatibility is higher. Previous studies on network 
externalities predominantly focus on equilibrium behavior under duopoly market or problems of industrial organization of single supply chain rather than competitive problems between two supply chains.

Competition between two supply chains has been proposed in many literatures. Mcguire and Staelin [18] analyze a vertical structure in the context of competitions at two manufacturers and two excusive retailers. They show that a decentralized distribution system strategically can shield manufacturers from price competition. Unlike Mcguire and Staelin's article, Coughlan [19] extends a linear demand function model to a more general demand function. Moorthy [20] focuses on the choice of manufacturer's channel structure and investigates the role of strategic interaction by using Mcguire and Staelin's model. Atkins and Zhao [21] examine the supply chain structure under competition framework through retail price and retailer's service. Xiong and Nie [22] use a price and advertising sensitive linear demand function and examine the equilibrium of price and the advertising level in centralized and decentralized structure.

Our paper is particularly relevant to studies on the supply chains under demand uncertainty. Wu and Chen [23] focus on the channel structures of two supply chains facing demand uncertainty scenario. Wu et al. [24] analyze a dual-channel distribution system design under demand uncertainty. They concentrate on considering different scenarios to show the impact of product substitutability and demand uncertainty on the equilibrium channel structure. Under basic chainto-chain framework, Wu et al. [25] investigate the equilibrium behavior and coordination when retailers face demand uncertainty. Xiao and Yang [26] analyze the competition through the price and service as the factors which could affect the demand and address risk sensitivity on the retailers' side. They suggest that the retailers' risk sensitivity and demand uncertainty can affect the players' optimal decisions. Xiao and Yang [27] consider the scenario in which one-retailer to one-manufacturer supply chain competes with an integrated supply chain. They explore the impact of demand uncertainty and risk-sharing rule on the revelation information mechanism designed by the manufacturer. Chai et al. [28] develop a model in which one supplier supplies products to two competitive retailers simultaneously. Two retailers face demand disruption and they compete with retail price through decentralized or centralized structure. However, effects of network externalities have not been examined in this stream of literature.

Contract has been applied as an important approach in chain-to-chain competition. Ha and Tong [29] use a two-stage game to analyze how the contract menus and linear price contracts affect information sharing value in two competitive and exclusive supply chains. Shou [30] studies the equilibrium decisions and contract terms on supply chain management when two competing supply chains face supply uncertainty. They obtain that, for a supply chain with linear contract, a coordinating contract can make both supplier and retailer better off regardless of whether the other supply chain coordinates or not. The profit-sharing contract has been applied as an important approach in many industries facing competition among firms. For instance, Rolls Royce signed profit-sharing contracts with its upstream global suppliers to develop the Trent 500 engine. Yao et al. [31] investigate a profit-sharing contract under two competing retailers who face stochastic demand. They find that profit-sharing contract can effectively improve the supply chain performance. The intensity of competition between the retailers makes system efficiency be higher. Our paper is related to Yao et al.; however, there is difference in the decision structure. We consider the competition between two supply chains under network externalities. Moreover, we examine the impact of the network externalities on the product substitution intensity and profit-sharing contract.

The rest of this paper is organized as follows. Considering the network externalities and demand uncertainty, the model of two competitive supply chains is described in Section 2. Under supply chain competition, RR case, WW case, and RW case are discussed in Section 3. In Section 4, we analyze and compare profit-sharing contract and wholesale price contract. Section 5 concludes marks and possible future work.

\section{The Basic Model}

We present models for two competitive supply chains facing demand uncertainty in a common market. Each manufacturer sells substitutable products with network externalities to the specific retailer and his unit production cost could be zero.

The sequence of decision-making is as follows:

(1) Contract Decision. Both manufacturers of competitive supply chains offer a contract to their own retailer simultaneously. Each manufacturer chooses either a profit-sharing contract or a wholesale price contract.

(2) Price Decision. (a) If a profit-sharing contract is offered in stage 1 , based on the demand forecasts, the supply chain members should integrate to decide the retail price and the profit share. (b) If a wholesale price contract is offered, the manufacturer decides the optimal wholesale price. Given the wholesale price, the retailer decides retail price based on the demand forecasts.

(3) Competition. Based on the contract price decisions, horizontal competition between two supply chains is formed.

According to the definition of network externality $[5,6]$ and the expression of linear demand function, the inverse demand functions for the supply chains with network externalities are

$$
p_{i}=a-q_{i}-b q_{j}+f\left(q_{i}^{e}\right), \quad j=3-i, i=1,2
$$

$p_{i}$ is the retail price, $q_{i}$ represents the selling quantity, and $q_{i}^{e}$ is the expected network size of product $i . f\left(q_{i}^{e}\right)$ is networkexternality function. We assume that $q_{i}^{e}=q_{i}$ and $f\left(q_{i}^{e}\right)=\mu q_{i}$; $\mu \in(0,1)$ is the degree of network externality. So the inverse demand functions for the supply chains can be written as

$$
p_{i}=a-q_{i}-b q_{j}+\mu q_{i}, \quad j=3-i, \quad i=1,2 .
$$


The corresponding demand functions are

$$
q_{i}=\frac{a b-a+\mu a+p_{i}-\mu p_{i}-b p_{j}}{b^{2}-1+2 \mu-\mu^{2}}, \begin{aligned}
& j=3-i, \quad i=1,2 .
\end{aligned}
$$

$a=1+e, \quad e \sim N(0, v)$,

where $a$ is the potential market size and its mean is $1 ; e$ presents the uncertainty due to the uncertainty of consumer awareness. We assume that $e$ is a normal distribution and its mean and variance, respectively, are 0 and $v . b$ is the product substitution coefficient between two supply chains. Following Vives [32] and Raju and Roy [33], in the common market, each retailer can obtain a forecast $a$ as $f_{i}$, and $f_{i}$ characters the forecasting error. Seals season coming, two supply chains have the experience in selling the products and introduce $\sqrt{v}$ in the forecasting model; then the information of the retail is

$$
f_{i}=a+\sqrt{v} \varepsilon_{i}, \quad \varepsilon_{i} \sim N(0, s), i=1,2 .
$$

$\varepsilon_{i}$ is a random variable which reflects the retailer's market forecast error with mean 0 and variance $s$. Consider $a_{i}=E(a \mid$ $\left.f_{i}\right)=1-t+t f_{i}$, where $t=1 /(1+s)$ for $t \in(0,1]$ is a measure of forecasting precision. We suppose that the information of the two retailers is independent, so we have $E\left(f_{j} \mid f_{i}\right)=1+$ $t\left(f_{i}-1\right)$ and $E\left(f_{i}-1\right)^{2}=v(1+s)=v / t$.

\section{Contracts under Supply Chain Competition}

3.1. RR Case: Both Supply Chains Are Integrated through ProfitSharing Contract. We discuss the case in which each manufacturer chooses a profit-sharing contract. In the RR case, both supply chains are integrated. Given its own retailer's forecast, each supply chain's purpose is to make the supply chain's conditional expected profit maximize. Under network externalities and demand uncertainty, the expected profits of both supply chains are

$$
\max _{p_{i}} E\left(T_{i} \mid f_{i}\right)=p_{i} E\left(q_{i} \mid f_{i}\right)
$$

As to the optimal price for each supply chain in the RR case, the following lemma is obtained.

Lemma 1. The retail price equilibrium for both supply chains, denoted as $p_{\text {irr }}$, is

$$
p_{i r r}=\frac{(b+\mu-1)}{(b+2 \mu-2)}+t\left(f_{i}-1\right) \frac{(b+\mu-1)}{(b t+2 \mu-2)} .
$$

This lemma means that, in an RR market, the supply chain's optimal retail price is existent and unique.

From Lemma 1, we get the expected profits of both supply chains as

$$
\begin{aligned}
& E T_{i \mathrm{rr}} \\
& =\frac{(1-\mu)(b+\mu-1)\left[t v(b+2 \mu-2)^{2}+(b t+2 \mu-2)^{2}\right]}{(\mu-1-b)(b t+2 \mu-2)^{2}(b+2 \mu-2)^{2}} .
\end{aligned}
$$

When a profit-sharing contract is offered, for each supply chain, supply chain members determine the retailer's profit share $r$, and the manufacturer's profit share is $1-r$.

From (7), the expected profits of the manufacturers and the retailers, denoted as $E R_{i \mathrm{rr}}$ and $E M_{i \mathrm{rr}}$, are

$$
\begin{aligned}
& E R_{i \mathrm{rr}}=\frac{r(1-\mu)(b+\mu-1)\left[t v(b+2 \mu-2)^{2}+(b t+2 \mu-2)^{2}\right]}{(\mu-1-b)(b t+2 \mu-2)^{2}(b+2 \mu-2)^{2}}, \\
& E M_{i \mathrm{rr}} \\
& =\frac{(1-r)(1-\mu)(b+\mu-1)\left[t v(b+2 \mu-2)^{2}+(b t+2 \mu-2)^{2}\right]}{(\mu-1-b)(b t+2 \mu-2)^{2}(b+2 \mu-2)^{2}} .
\end{aligned}
$$

3.2. WW Case: Both Supply Chains Choose Wholesale Price Contract. In the WW case, the wholesale price contracts would be offered by the manufacturers. Manufacture $i$ intends to make its own profit maximize by setting the wholesale price $w_{i}$. When the retailer $i$ accepts the wholesale price, then he decides $p_{i}$ to optimize his conditional expected profit given its own forecast. The expected profit of retailer $i$, given a forecast, is

$$
\max _{p_{i}} E\left(R_{i} \mid f_{i}\right)=\left(p_{i}-w_{i}\right) E\left(q_{i} \mid f_{i}\right) .
$$

The profit of manufacturer $i$ is

$$
\max _{w_{i}} E\left(M_{i}\right)=w_{i} E\left(q_{i}\right) .
$$

As to the manufacturer's and retail's optimal price in the WW case, the following lemma is obtained.

Lemma 2. The wholesale price and retail price equilibrium for both supply chains, denoted as $w_{i w w}$ and $p_{i w w}$, are

$$
\begin{aligned}
& w_{i w w}=\frac{2(b+\mu-1)}{(3 b+4 \mu-4)} \\
& p_{i w w}=\frac{3(b+\mu-1)}{(3 b+4 \mu-4)}+t\left(f_{i}-1\right) \frac{(b+\mu-1)}{(b t+2 \mu-2)} .
\end{aligned}
$$

Lemma 2 means that, in the WW market, the manufacturer's optimal price decision is existent and unique and the retail's price decision relies on the forecast.

From Lemma 2, the expected profits of the retails and the manufacturers, denoted as $E R_{i \mathrm{ww}}$ and $E M_{i \mathrm{ww}}$, are

$$
\begin{aligned}
& E R_{i \mathrm{Ww}} \\
& =\frac{(1-\mu)(b+\mu-1)\left[t v(3 b+4 \mu-4)^{2}+(b t+2 \mu-2)^{2}\right]}{(\mu-1-b)(b t+2 \mu-2)^{2}(3 b+4 \mu-4)^{2}}, \\
& E M_{i \mathrm{Ww}}=\frac{(1-\mu)(b+\mu-1)}{(\mu-1-b)(3 b+4 \mu-4)^{2}} .
\end{aligned}
$$

From (12), the expected profits of both supply chains, denoted as $E T_{i \mathrm{wW}}$, are

$$
\begin{aligned}
& E T_{i \mathrm{ww}} \\
& =\frac{(1-\mu)(b+\mu-1)\left[t v(3 b+4 \mu-4)^{2}+3(b t+2 \mu-2)^{2}\right]}{(\mu-1-b)(b t+2 \mu-2)^{2}(3 b+4 \mu-4)^{2}} .
\end{aligned}
$$


3.3. RW Case: The First Supply Chain Chooses a Profit-Sharing Contract and the Second Supply Chain Chooses Wholesale Price Contract. In the RW case, we suppose the first supply chain offers a profit-sharing contract to its own retailer, while the second supply chain chooses the other contract. The first supply chain's expected profit conditioned on the forecast of retailer 1 is

$$
\max _{p_{1}} E\left(T_{1} \mid f_{1}\right)=p_{1} E\left(q_{1} \mid f_{1}\right)
$$

Retailer 2's expected profit conditioned on his own forecast and the profit of the manufacturer 2, respectively, is

$$
\begin{aligned}
\max _{p_{2}} E\left(R_{2} \mid f_{2}\right) & =\left(p_{2}-w_{2}\right) E\left(q_{2} \mid f_{2}\right), \\
\max _{w_{2}} E\left(M_{2}\right) & =w_{2} E\left(q_{2}\right) .
\end{aligned}
$$

As to the optimal retail price of the first supply chain and the optimal choice for wholesale price and retail price of the second supply chain in the RW case, the following lemma is obtained.
Lemma 3. Using backward induction, we obtain the optimal retail price of the first supply chain, and the optimal choice for wholesale price and retail price of the second supply chain, denoted as $p_{1 r w}, w_{2 r w}$, and $p_{2 r w}$, are

$$
\begin{aligned}
p_{1 r w}= & \frac{\mu b-8 \mu+4 \mu^{2}-b+4-3 b^{2}}{-3 b^{2}-16 \mu+8 \mu^{2}+8} \\
& +t\left(f_{1}-1\right) \frac{(b+\mu-1)}{(b t+2 \mu-2)}, \\
p_{2 r w}= & \frac{3 \mu b-12 \mu+6 \mu^{2}-3 b+6-3 b^{2}}{-3 b^{2}-16 \mu+8 \mu^{2}+8} \\
& +t\left(f_{2}-1\right) \frac{(b+\mu-1)}{(b t+2 \mu-2)}, \\
w_{2 r w}= & \frac{2(b+\mu-1)(b-2 \mu+2)}{3 b^{2}+16 \mu-8 \mu^{2}-8} .
\end{aligned}
$$

From Lemma 3, the expected profit of supply chain 1, denoted as $E T_{1 \mathrm{rw}}$, is

$$
E T_{1 \mathrm{rw}}=\frac{(1-\mu)(b+\mu-1)\left[t v\left(-3 b^{2}-16 \mu+8 \mu^{2}+8\right)^{2}+(b t+2 \mu-2)^{2}(3 b+4 \mu-4)^{2}\right]}{(\mu-1-b)(b t+2 \mu-2)^{2}\left(-3 b^{2}-16 \mu+8 \mu^{2}+8\right)^{2}} .
$$

Supply chain members share the profit of the integrated chain; from (20), the expected profits of manufacturer 1 and retailer 1 in the first supply chain, denoted as $E R_{1 \mathrm{rw}}$ and $E M_{1 \mathrm{rw}}$, are

$$
\begin{aligned}
E R_{1 \mathrm{rw}} & =\frac{r(1-\mu)(b+\mu-1)\left[t v\left(-3 b^{2}-16 \mu+8 \mu^{2}+8\right)^{2}+(b t+2 \mu-2)^{2}(3 b+4 \mu-4)^{2}\right]}{(\mu-1-b)(b t+2 \mu-2)^{2}\left(-3 b^{2}-16 \mu+8 \mu^{2}+8\right)^{2}}, \\
E M_{1 \mathrm{rw}} & =\frac{(1-r)(1-\mu)(b+\mu-1)\left[t v\left(-3 b^{2}-16 \mu+8 \mu^{2}+8\right)^{2}+(b t+2 \mu-2)^{2}(3 b+4 \mu-4)^{2}\right]}{(\mu-1-b)(b t+2 \mu-2)^{2}\left(-3 b^{2}-16 \mu+8 \mu^{2}+8\right)^{2}} .
\end{aligned}
$$

From (18) and (19), the expected profits of manufacturer 2 and retailer 2 in the second supply chain, denoted as $E R_{2 \mathrm{rw}}$ and $E M_{2 \mathrm{rw}}$, are

$$
\begin{aligned}
E R_{2 \mathrm{rw}} & =\frac{(1-\mu)(b+\mu-1)\left[t v\left(-3 b^{2}-16 \mu+8 \mu^{2}+8\right)^{2}+(b t+2 \mu-2)^{2}(b-2 \mu+2)^{2}\right]}{(\mu-1-b)(b t+2 \mu-2)^{2}\left(-3 b^{2}-16 \mu+8 \mu^{2}+8\right)^{2}}, \\
E M_{2 \mathrm{rw}} & =\frac{2(1-\mu)(b+\mu-1)(2 \mu-2-b)^{2}}{(\mu-1-b)(3 b+4 \mu-4)^{2}\left(-3 b^{2}-16 \mu+8 \mu^{2}+8\right)^{2}} .
\end{aligned}
$$


Then the second supply chain's expected profit, denoted as $E T_{2 \mathrm{rw}}$, is

$$
E T_{2 \mathrm{rw}}=\frac{(1-\mu)(b+\mu-1)\left[t v\left(-3 b^{2}-16 \mu+8 \mu^{2}+8\right)^{2}+3(b t+2 \mu-2)^{2}(b-2 \mu+2)^{2}\right]}{(\mu-1-b)(b t+2 \mu-2)^{2}\left(-3 b^{2}-16 \mu+8 \mu^{2}+8\right)^{2}} .
$$

Taking (5)-(23) into account, the optimal decisions must be greater than zero; we can easily derive that $0<\mu<1$ and $0<b<b_{0}$, where $b_{0}=(1-\mu)$.

\section{Analysis and Comparison of Contracts}

4.1. When Both Supply Chains Choose a Profit-Sharing Contract or a Wholesale Price Contract. From Lemmas 1 and 2, we can compute $E R_{1 \mathrm{rr}}-E R_{1 \mathrm{ww}}$ and $E M_{1 \mathrm{rr}}-E M_{1 \mathrm{ww}}$ and derive

$$
\begin{aligned}
E R_{1 \mathrm{rr}}-E R_{1 \mathrm{ww}}= & \frac{(1-\mu)(b+\mu-1)\left[t v(b+2 \mu-2)^{2}+(b t+2 \mu-2)^{2}\right]\left(r-r_{1}\right)}{(\mu-1-b)(b t+2 \mu-2)^{2}(b+2 \mu-2)^{2}}, \\
E M_{1 \mathrm{rr}}-E M_{1 \mathrm{ww}} & =\frac{-(1-\mu)(b+\mu-1)\left[t v(b+2 \mu-2)^{2}+(b t+2 \mu-2)^{2}\right]\left(r-r_{4}\right)}{(\mu-1-b)(b t+2 \mu-2)^{2}(b+2 \mu-2)^{2}},
\end{aligned}
$$

where $r_{1}$ and $r_{4}$ are threshold values for $E R_{1 \mathrm{rr}}=E R_{1 \mathrm{ww}}$ and $E M_{1 \mathrm{rr}}=E M_{1 \mathrm{ww}}$, respectively:

$$
\begin{aligned}
& r_{1}=\frac{(b+2 \mu-2)^{2}\left[t v(3 b-4 \mu-4)^{2}+(b t+2 \mu-2)^{2}\right]}{(3 b-4 \mu-4)^{2}\left[t v(b t+2 \mu-2)^{2}+(b+2 \mu-2)^{2}\right]}, \\
& r_{4}=\frac{t v(b+2 \mu-2)^{2}(3 b+4 \mu-4)^{2}+(b t+2 \mu-2)^{2}\left(7 b^{2}+8 \mu^{2}-16 b-16 \mu+16 b \mu\right)}{(3 b+4 \mu-4)^{2}\left[t v(b+2 \mu-2)^{2}+(b t+2 \mu-2)^{2}\right]} .
\end{aligned}
$$

Comparison of $r_{1}$ to $r_{4}$, denoted as $r_{1}-r_{4}$, is as follows:

$$
r_{1}-r_{4}=\frac{-2(b-0.4426(1-\mu))(b-1.5774(1-\mu))(b t+2 \mu-2)^{2}}{t(3 b+4 \mu-4)^{2}(b+2 \mu-2)^{2}\left(v+(b t+2 \mu-2)^{2} / t(b+2 \mu-2)^{2}\right)} .
$$

Lemma 4. If $0<\mu<1,0<b<0.4226(1-\mu)$, then $r_{1}<r_{4}$.

Proposition 5. If $0<\mu<1,0<b<0.4226(1-\mu)$, when profit share is in the range of $r_{1}<r<r_{4}$, both competing supply chains prefer a profit-sharing contract, since $E R_{i r r}>E R_{i w w}$ and $E M_{i r r}>E M_{i w w}$.

This proposition means that when the products offered by both supply chains exhibit network externalities, the product substitutability coefficient $b$ in two competitive supply chains system depends on the network-externality parameter.
Furthermore, the retailers' profit share range depends on the network-externality parameter, product substitutability, and the demand uncertainty. Under demand uncertainty, if the product substitutability coefficient is below $0.4226(1-$ $\mu$ ) and if retailers can accept a profit share in the range $\left(r_{1}, r_{4}\right)$, a profit-sharing contract is a better strategy for either manufacturers or retailers in two competitive supply chains.

4.2. When the Second Supply Chain Chooses a Wholesale Price Contract. From Lemmas 2 and 3, we can compute $E R_{1 \mathrm{rw}}-$ $E R_{1 \mathrm{ww}}$ and $E M_{1 \mathrm{rw}}-E M_{1 \mathrm{ww}}$ and derive 


$$
\begin{aligned}
& E R_{1 \mathrm{rw}}-E R_{1 \mathrm{ww}}=\frac{(1-\mu)(b+\mu-1)\left[t v\left(3 b^{2}-8 \mu^{2}+16 \mu-8\right)^{2}+(b t+2 \mu-2)^{2}(3 b+4 \mu-4)^{2}\right]\left(r-r_{2}\right)}{(\mu-1-b)(b t+2 \mu-2)^{2}\left(3 b^{2}-8 \mu^{2}+16 \mu-8\right)^{2}}, \\
& E M_{1 \mathrm{rw}}-E M_{1 \mathrm{ww}} \\
& =\frac{-(1-\mu)(b+\mu-1)\left[t v\left(3 b^{2}-8 \mu^{2}+16 \mu-8\right)^{2}(3 b+4 \mu-4)^{2}+(b t+2 \mu-2)^{2}(3 b-4 \mu+4)^{2}\right]\left(r-r_{5}\right)}{(\mu-1-b)(b t+2 \mu-2)^{2}\left(3 b^{2}-8 \mu^{2}+16 \mu-8\right)^{2}}
\end{aligned}
$$

where $r_{2}$ and $r_{5}$ are threshold values for $E R_{1 \mathrm{rw}}=E R_{1 \mathrm{ww}}$ and

$E M_{1 \mathrm{rw}}=E M_{1 \mathrm{ww}}$, respectively:

$$
\begin{aligned}
& r_{2}=\frac{\left(3 b^{2}-8 \mu^{2}+16 \mu-8\right)^{2}\left[t v(3 b+4 \mu-4)^{2}+(b t+2 \mu-2)^{2}\right]}{\left[t v(3 b+4 \mu-4)^{2}\left(3 b^{2}-8 \mu^{2}+16 \mu-8\right)^{2}+(3 b+4 \mu-4)^{2}(3 b-4 \mu+4)^{2}(b t+2 \mu-2)^{2}\right]}, \\
& r_{5} \\
& =\frac{t v(3 b+4 \mu-4)^{2}+(b t+2 \mu-2)^{2}\left(3 b^{2}-8 \mu^{2}+16 \mu-8\right)^{2}+\left(63 b^{4}-512 \mu^{3}+384 b^{2} \mu-512 \mu+128+768 \mu^{2}-192 b^{2} 128 \mu^{4}-192 b^{2} \mu^{2}\right)}{\left[t v(3 b+4 \mu-4)^{2}\left(3 b^{2}-8 \mu^{2}+16 \mu-8\right)^{2}+(3 b+4 \mu-4)^{2}(3 b-4 \mu+4)^{2}(b t+2 \mu-2)^{2}\right]} .
\end{aligned}
$$

Comparison of $r_{2}$ to $r_{5}$, denoted as $r_{2}-r_{5}$, is as follows:

$$
r_{2}-r_{5}=\frac{-54(b-0.7507(1-\mu))(b+0.7507(1-\mu))(b-1.4502(1-\mu))(b+1.4502(1-\mu))(b t+2 \mu-2)^{2}}{t(3 b+4 \mu-4)^{2}\left(3 b^{2}-8 \mu^{2}+16 \mu-8\right)^{2}\left(v+(b t+2 \mu-2)^{2}(3 b+4 \mu-4)^{2} / t\left(3 b^{2}-8 \mu^{2}+16 \mu-8\right)^{2}\right)}
$$

Lemma 6. If $0<\mu<1,0<b<0.7505(1-\mu)$, then $r_{2}<r_{5}$.

Proposition 7. If $0<\mu<1,0<b<0.7507(1-\mu)$, when the second supply chain offers a wholesale price contract, in case the profit share of retailer 1 is in the range of $r_{2}<r<r_{5}$, the first chain has an incentive to choose a profit-sharing contract, since $E R_{1 r w}>E R_{1 w w}$ and $E M_{1 r w}>E M_{1 w w}$.

This proposition means that when the products offered by both supply chains exhibit network externalities, the product substitutability parameter $b$ in two competing supply chains system depends on the network-externality parameter.
Furthermore, the retailers' profit share range depends on the network-externality parameter, product substitutability, and the demand uncertainty. Under demand uncertainty, if the degree of product substitutability is below $0.7507(1-\mu)$ and if retailers can accept a profit share in the range $\left(r_{2}, r_{5}\right)$, in case the second supply chain chooses a wholesale price contract, for the first supply chain, a profit-sharing contract is a better strategy for either manufacturer or retailer.

4.3. When the First Supply Chain Chooses a Profit-Sharing Contract. From Lemmas 1 and 3, we can compute $E R_{2 \mathrm{rr}}-$ $E R_{2 \mathrm{rw}}$ and $E M_{2 \mathrm{rr}}-E M_{2 \mathrm{rw}}$ and derive

$$
\begin{gathered}
E R_{2 \mathrm{rr}}-E R_{2 \mathrm{rw}}=\frac{(1-\mu)(b+\mu-1)\left[t v(b+2 \mu-2)^{2}+(b t+2 \mu-2)^{2}\right]\left(r-r_{3}\right)}{(\mu-1-b)(b t+2 \mu-2)^{2}(b+2 \mu-2)^{2}}, \\
E M_{2 \mathrm{rr}}-E M_{2 \mathrm{rw}}=\frac{-(1-\mu)(b+\mu-1)\left[t v(b+2 \mu-2)^{2}+(b t+2 \mu-2)^{2}\right]\left(r-r_{6}\right)}{(\mu-1-b)(b t+2 \mu-2)^{2}(b+2 \mu-2)^{2}},
\end{gathered}
$$


where $r_{3}$ and $r_{6}$ are threshold values for $E R_{2 \mathrm{rr}}=E R_{2 \mathrm{rw}}$ and

$E M_{2 \mathrm{rr}}=E M_{2 \mathrm{rw}}$, respectively:

$$
\begin{aligned}
& r_{3}=\frac{(b+2 \mu-2)^{2}\left[t v\left(3 b^{2}-8 \mu^{2}+16 \mu-8\right)^{2}+(b+2 \mu-2)^{2}(b t+2 \mu-2)^{2}\right]}{\left[t v(b+2 \mu-2)^{2}+(b t+2 \mu-2)^{2}\right]\left(3 b^{2}-8 \mu^{2}+16 \mu-8\right)^{2}}, \\
& r_{6} \\
& =\frac{\left[t v(b+2 \mu-2)^{2}\left(3 b^{2}-8 \mu^{2}+16 \mu-8\right)^{2}+(b+2 \mu-2)^{2}\left(7 b^{4}-128 \mu^{3}+64 b^{2} \mu-128 \mu+32+192 \mu^{2}-32 b^{2}+32 \mu^{4}-32 b^{2} \mu^{2}\right)\right]}{\left[t v(b+2 \mu-2)^{2}+(b t+2 \mu-2)^{2}\right]\left(3 b^{2}-8 \mu^{2}+16 \mu-8\right)^{2}}, \\
& r_{3}-r_{6}=\frac{-6(b-0.9194(1-\mu))(b+0.9194(1-\mu))(b-1.7761(1-\mu))(b+1.7761(1-\mu))(b t+2 \mu-2)^{2}}{t(b+2 \mu-2)^{2}\left(3 b^{2}-8 \mu^{2}+16 \mu-8\right)^{2}\left(v+(b t+2 \mu-2)^{2} / t(b+2 \mu-2)^{2}\right)} .
\end{aligned}
$$

Lemma 8. If $0<\mu<1,0<b<0.9194(1-\mu)$, then $r_{3}<r_{6}$.

Proposition 9. If $0<\mu<1,0<b<0.9194(1-\mu)$, when profit share is in the range of $r_{3}<r<r_{6}$ and the first supply chain offers a profit-sharing contract, the second supply chain has an incentive to offer a wholesale price contract, since $E R_{2 r r}>E R_{2 r w}$ and $E M_{2 r r}>E M_{2 r w}$.

This proposition means that when the products offered by both supply chains have network externalities, the product substitutability coefficient in two competitive supply chains system depends on the network-externality parameter. Furthermore, the retailers' profit share range depends on the network-externality parameter, product substitutability, and the demand uncertainty. Under demand uncertainty, if the degree of product substitutability is below $0.9194(1-\mu)$ and if retailers can accept a profit share in the range $\left(r_{3}, r_{6}\right)$, for the second supply chain, once the first supply chain offers a profit-sharing contract, a profit-sharing contract is a better strategy for either manufacturer or retailer.

\subsection{Contract Evolution Analysis}

Lemma 10. If $0<\mu<1,0<b<0.4226(1-\mu)$, then $r_{1}>r_{2}$, $r_{1}>r_{3}$, and $r_{1}<r_{4}<r_{5}<r_{6}$.

Proposition 11. If $0<\mu<1,0<b<0.4226(1-\mu)$, and $r_{1}<r<r_{4}$, contract evolution of competitive supply chains is $w w \rightarrow w r / r w \rightarrow r r$.

This proposition means that when the products offered by both supply chains exhibit network externalities, the product substitutability coefficient $b$ in two competitive supply chains system depends on the network-externality parameter. Furthermore, the retailers' profit share range depends on the network-externality parameter, product substitutability coefficient, and the demand uncertainty. If product substitutability coefficient $b$ is below $0.4226(1-\mu)$ and if retailers can accept a profit share in the range $\left(r_{1}, r_{4}\right)$, the equilibrium contracts choice of competitive supply chains is profit-sharing contracts. When the profit-sharing contract is negotiated by the supply chain members, they can obtain Pareto improvement.

Proposition 12. If $0<\mu<1,0.4226(1-\mu)<b<1$, profitsharing contracts cannot be the equilibrium contracts choice of competitive supply chains. If a profit-sharing contract is offered, the manufacturer and retailer's profits could reduce.

Using a numerical example, we can illustrate the effect of the product substitutability coefficient on the retailer's profit share range. We set $t=0.2, v=0.5$, and $\mu=0.5$. The findings are shown in Figure 1.

Figure 1 shows that, in region $\mathrm{A}$, a profit-sharing contract could be a better strategy for the manufacturers and the retailers under the chain-to-chain competition. As the degree of product substitutability increases, the retailer's profit share range shrinks.

To illustrate the effect of the network-externality parameter on the retailer's profit share range, we use a numerical study and set $t=0.2, v=0.5$, and $b=0.1$. The results are shown in Figure 2.

Figure 2 shows that, in region $\mathrm{B}$, a profit-sharing contract could be a better strategy for the manufacturers and the retailers when they face competition between two supply chains. As the network-externality parameter increases, the retailer's profit share range shrinks.

\subsection{The Effect of the Demand Uncertainty}

Proposition 13. When $0<\mu<1,0<b<0.4226(1-\mu)$,

(1) we have $\partial r_{1} / \partial v>0$ and $\partial r_{4} / \partial v>0$;

(2) if $v \rightarrow \infty$, then $r_{1} \rightarrow 1$ and $r_{4} \rightarrow 1$.

This proposition means that when the products offered by both supply chains exhibit network externalities, the degree of product substitutability under the chain-to-chain competition depends on the network-externality parameter weekly; as the demand variance increases, the retailer's profit share could increase. When demand variance $(v)$ is higher, retailers' demand forecasting information becomes important for both supply chains. Because the retailers have 


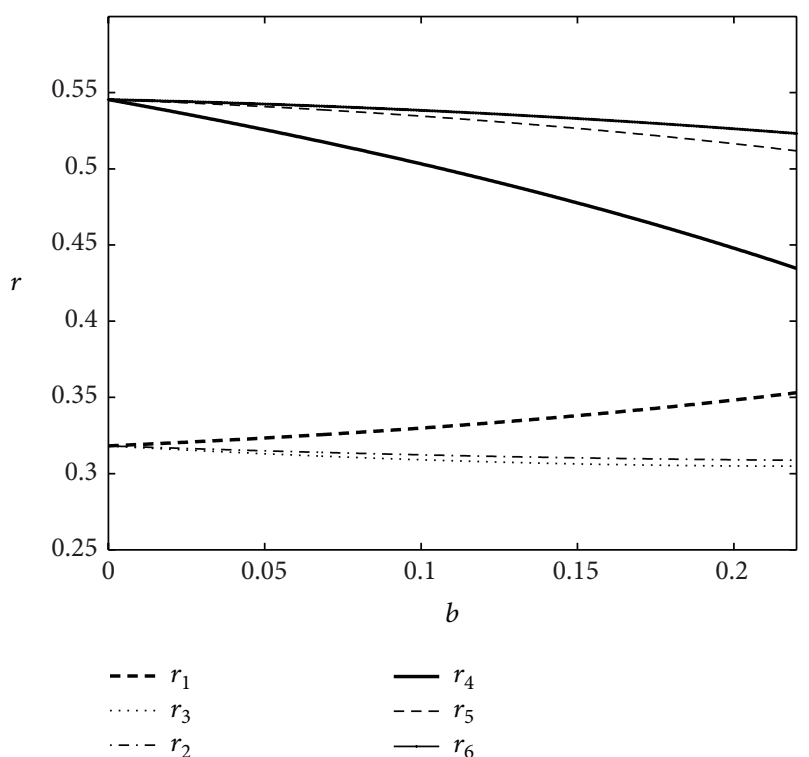

FIGURE 1: Effect of product substitutability coefficient on the profit share.

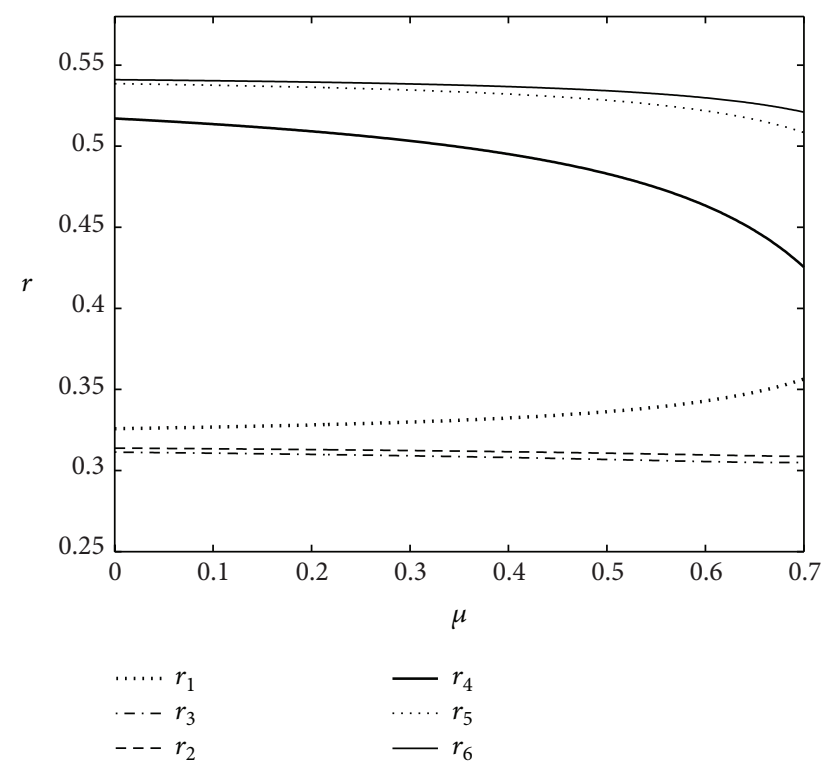

FIGURE 2: Effect of network-externality parameter on the profit share.

information superiority, they have strong bargaining power to negotiate a higher profit share. It also means that when demand variance $(v)$ is extremely high, that is, $v \rightarrow \infty$, the retailer's profit share is approaching 1 for having the advantage of obtaining demand forecasting information.

\section{Conclusions and Future Research}

Under the framework of demand uncertainty, we consult the competition between two supply chains. Each manufacturer produces substitutable products in the presence of network externalities to the retailer. We present the supply chain members' strategy decisions for different contract configurations and the equilibrium contract choice between the manufacturer and the retailer.

We show that the degree of network externality affects the product substitutability coefficient, and the degree of network externality and product substitutability coefficient affect profit share range. We also show that when the impact of network externality on the product substitutability coefficient is not strong $(b \in(0,0.4226(1-\mu)))$ and the retailer can negotiate a profit share in the range $\left(r_{1}, r_{4}\right)$, the vertical alliance contributes profit improvement to both the manufacturer and the retailer; however, vertical alliance will be out of operation when the impact of network externality on the product substitutability coefficient is strong. Furthermore, using a numerical study, this paper suggests that the profit share range of the retailer shrinks as the degree of product substitutability increases and shrinks as the networkexternality parameter increases.

There are several directions for future research. First of all, we assume that two supply chains' substitutability coefficients and the network-externality parameters are identical. The case with specific network-externality parameter in each supply chain might be interesting. Second, one extension of this work is to consider the case with risk-averse suppliers. Third, the case with multiple competing supply chains in the presence of network externalities could be challenging.

\section{Competing Interests}

The author declares that there are no competing interests regarding the publication of this paper.

\section{Acknowledgments}

This research is partially supported by the National Natural Science Foundation of China (nos. 71372140 and 71432003).

\section{References}

[1] T. Boyaci and G. Gallego, "Supply chain coordination in a market with customer service competition," Production and Operations Management, vol. 13, no. 1, pp. 3-22, 2004.

[2] D. Barnes, Competing Supply Chains are the Future, Financial Times, 2006.

[3] P. Majumder and A. Srinivasan, "Leadership and competition in network supply chains," Management Science, vol. 54, no. 6, pp. 1189-1204, 2008.

[4] X. Ai, J. Chen, H. Zhao, and X. Tang, "Competition among supply chains: implications of full returns policy," International Journal of Production Economics, vol. 139, no. 1, pp. 257-265, 2012.

[5] M. Katz and C. Shapiro, "Network externalities, competition, and compatibility," The American Economic Review, vol. 75, no. 3, pp. 424-440, 1985.

[6] M. L. Katz and C. Shapiro, "Technology adoption in the presence of network externalities," Journal of Political Economy, vol. 94, no. 4, pp. 822-841, 1986. 
[7] M. L. Katz and C. Shapiro, "Systems competition and network effects," Journal of Economic Perspectives, vol. 8, no. 2, pp. 93-115, 1994.

[8] C.-F. Chou and O. Shy, "Partial compatibility and supporting services," Economics Letters, vol. 41, no. 2, pp. 193-197, 1993.

[9] J. Xie and M. Sirbu, "Price competition and compatibility in the presence of positive demand externalities," Management Science, vol. 41, no. 5, pp. 909-926, 1995.

[10] T. Cottrell and K. Koput, "Software variety and hardware value: a case study of complementary network externalities in the microcomputer software industry," Journal of Engineering and Technology Management, vol. 15, no. 4, pp. 309-338, 1998.

[11] P. Baake and A. Boom, "Vertical product differentiation, network externalities, and compatibility decisions," International Journal of Industrial Organization, vol. 19, no. 1-2, pp. 267-284, 2001.

[12] $\varnothing$. Foros and B. Hansen, "Competition and compatibility among internet service providers," Information Economics and Policy, vol. 13, no. 4, pp. 411-425, 2001.

[13] T. Doganoglu and L. Grzybowski, "Dynamic duopoly competition with switching costs and network externalities," Review of Network Economics, vol. 12, no. 1, pp. 1-25, 2013.

[14] S. Viswanathan, "Competing across technology-differentiated channels: the impact of network externalities and switching costs," Management Science, vol. 51, no. 3, pp. 483-496, 2005.

[15] S. Hoernig, "Strategic delegation under price competition and network effects," Economics Letters, vol. 117, no. 2, pp. 487-489, 2012.

[16] A. Chirco and M. Scrimitore, "Choosing price or quantity? The role of delegation and network externalities," Economics Letters, vol. 121, no. 3, pp. 482-486, 2013.

[17] H.-C. Chen and C.-C. Chen, "Compatibility under differentiated duopoly with network externalities," Journal of Industry, Competition and Trade, vol. 11, no. 1, pp. 43-55, 2011.

[18] C. T. W. Mcguire and R. Staelin, "An industry equilibrium analysis of downstream vertical integration," Marketing Science, vol. 2, no. 2, pp. 161-191, 1983.

[19] A. T. Coughlan, "Competition and cooperation in marketing channel choice: theory and application," Marketing Science, vol. 4, no. 2, pp. 110-129, 1985.

[20] K. S. Moorthy, "Strategic decentralization in channels," Marketing Science, vol. 7, no. 4, pp. 335-355, 1988.

[21] D. Atkins and X. Zhao, Supply Chain Structure under Price and Service Competition, University of British Columbia Working Paper, 2002.

[22] Z. Xiong and J. Nie, "Optimal pricing and advertising competition in two supply chains with deterministic demand," International Journal of Manufacturing Technology and Management, vol. 17, no. 3, pp. 289-314, 2009.

[23] Q. Q. Wu and H. Chen, Chain-to-Chain Competition under Demand Uncertainty, The University of British Columbia, Vancouver, Canada, 2003.

[24] C. Wu, N. C. Petruzzi, and D. Chhajed, "Vertical integration with price-setting competitive newsvendors," Decision Sciences, vol. 38, no. 4, pp. 581-610, 2007.

[25] D. Wu, O. Baron, and O. Berman, "Bargaining in competing supply chains with uncertainty," European Journal of Operational Research, vol. 197, no. 2, pp. 548-556, 2009.

[26] T. Xiao and D. Yang, "Price and service competition of supply chains with risk-averse retailers under demand uncertainty,"
International Journal of Production Economics, vol. 114, no. 1, pp. 187-200, 2008.

[27] T. Xiao and D. Yang, "Risk sharing and information revelation mechanism of a one-manufacturer and one-retailer supply chain facing an integrated competitor," European Journal of Operational Research, vol. 196, no. 3, pp. 1076-1085, 2009.

[28] W. L. Chai, H. J. Sun, W. Wei, and J. Wu, "Price competition model in decentralized and centralized supply chains with demand disruption," Journal of Industrial Engineering and Management, vol. 6, no. 1, pp. 16-24, 2013.

[29] A. Y. Ha and S. Tong, "Contracting and information sharing under supply chain competition," Management Science, vol. 54, no. 4, pp. 701-715, 2008.

[30] B. Shou, Managing Supply Uncertainty under Chain-to-Chain Competition, SSRN, 2009.

[31] Z. Yao, S. C. Leung, and K. K. Lai, "Manufacturer's revenuesharing contract and retail competition," European Journal of Operational Research, vol. 186, no. 2, pp. 637-651, 2008.

[32] X. Vives, "Duopoly information equilibrium: cournot and bertrand," Journal of Economic Theory, vol. 34, no. 1, pp. 71-94, 1984.

[33] J. S. Raju and A. Roy, "Market information and firm performance," Management Science, vol. 46, no. 8, pp. 1075-1084, 2000 . 


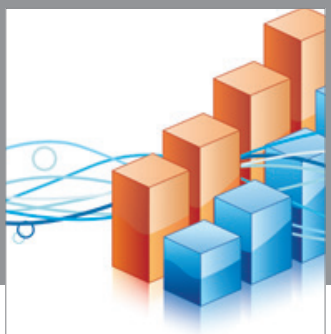

Advances in

Operations Research

vatem alat4

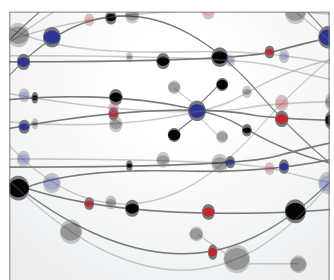

\section{The Scientific} World Journal
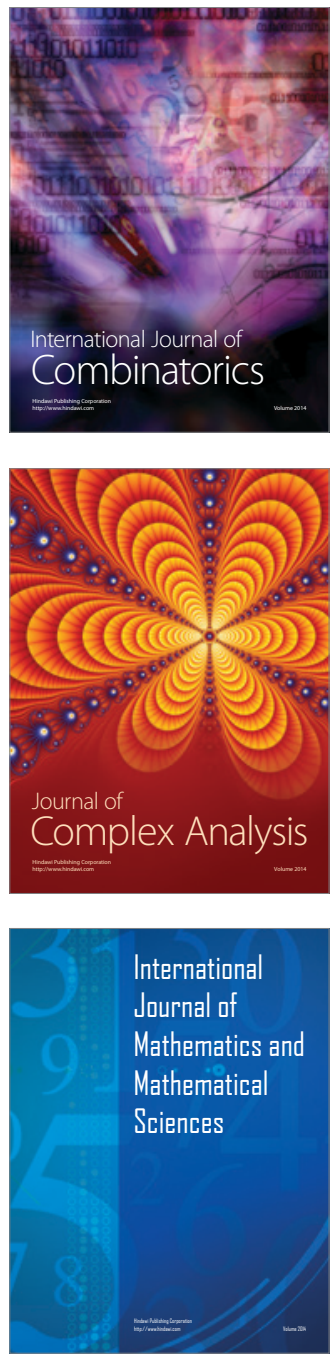
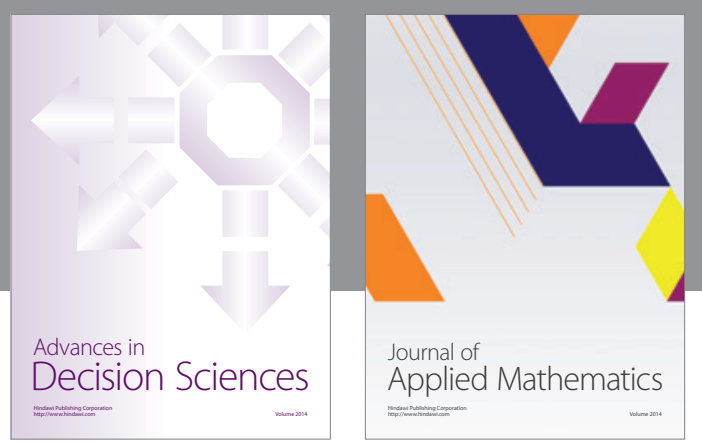

Algebra

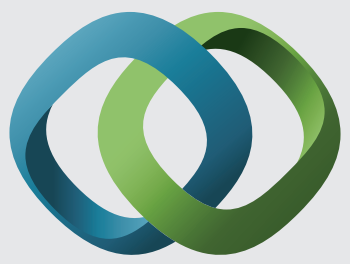

\section{Hindawi}

Submit your manuscripts at

http://www.hindawi.com
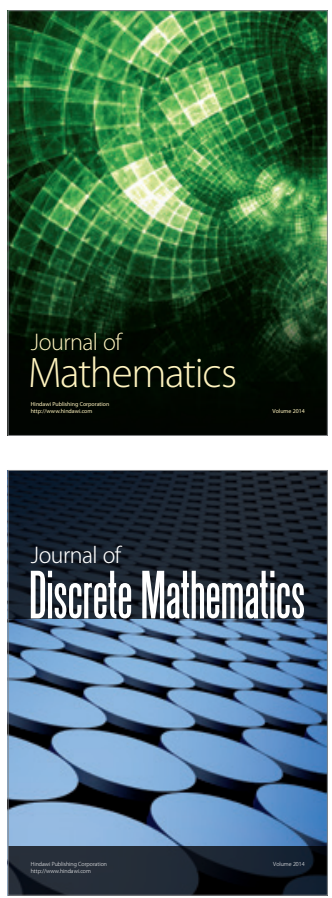

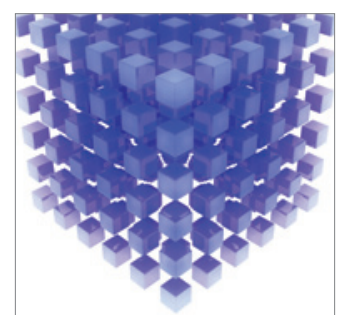

Mathematical Problems in Engineering
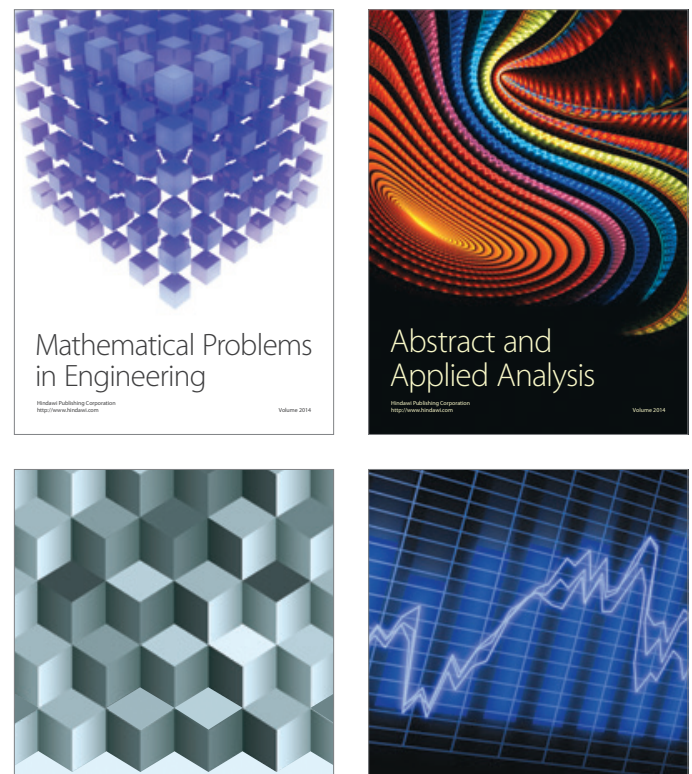

Journal of

Function Spaces

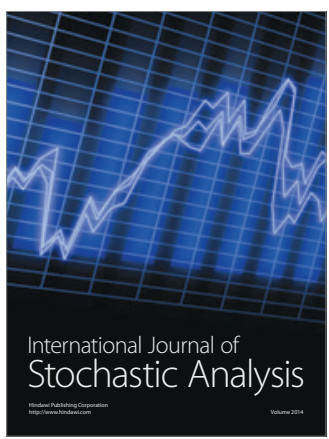

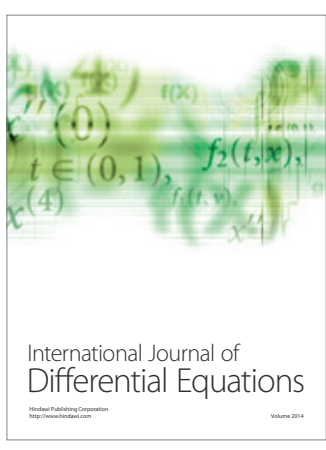
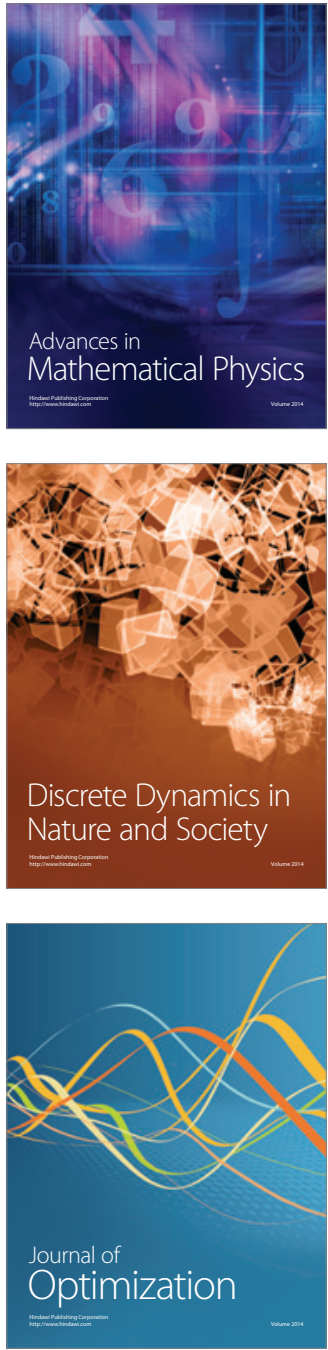